\title{
Will There be Enough Food on the Table?
}

\author{
JOHN E. ROSS \\ Environmental Studies and Agricultural Journalism, University of Wisconsin-Madison, WI, USA
}

(Received 16 November 1998)

\section{SETTING THE STAGE}

I'll answer the question posed in my title - at the start of this paper.

Will there be enough food on the table?

My answer: No. Not without an increasing commitment in research, technology, investment and political will. And, perhaps most importantly, not without the resolution of some consequential environmental problems. As we proceed, you can assess my judgment.

There are two underlying paradigms in this paper:

(1) The number of people alive and well in the world in any given year depends fundamentally on the volume and quality of available food. Most other population issues flow from this one, including death rates. Potable water is the only variable more fundamental than food.

(2) Sustainability of the food production base is the central agricultural issue. We will continue to rely on natural resources of energy, arable land, water, and climate-driven temperature. In other words, we will not shift to the production of food in chemical vats in the foreseeable future.
It is painfully obvious that per capita availability of food now does vary greatly among societies. Vast populations do not have an adequate diet, while others have a surfeit.

Thus, we must think about the quantity of food, but also the quality.

\section{POPULATION}

I do need to make some population projections as related to food supply. We don't want to get bogged down in arguments over the precision of those projections, but let us lay out some of the demographic parameters.

If world population continues to increase at its current annual rate of $90+$ million per year, the population will increase nearly a billion in the next decade. (As a reference point: In 1950, in the early stages of the Green Revolution, the average annual increase was around 30 million per year.) With a continuation of the current rate, world population would reach about 8.3 billion in the year 2025 . Considering current downward trends in birth rates, the rate of growth may well decline. 
According to current UN projections, population will have risen from its current 5.6 billion, to at least 7.9 billion by the year 2050 . However, it is possible that total population will be closer to 9.8 billion by 2050, and it could reach 11.9 billion (Vital Signs 1995).

In another scenario, The Winrock International Institute for Agricultural Development accepts a World Bank projection of 7.8 billion in 2050 but predicts zero growth at that time, and a net decline to just over 6 billion by the year 2100 . The Winrock Institute foresees some major crises along the way, for example, "The population outlook for most of sub-Saharan Africa is grim; we fear that a true Malthusian disaster is brewing there." But, they continue, "we believe that one of the major forces in reducing fertility rates in developing countries is the rapid spread of modern self-images and life styles..." Thus, they continue to accept the classical demographic transition.

There is an obvious imbalance in food supplies and nutritional quality among the countries. The 1990 figures show that $66 \%$ of the children in Bangladesh were listed as underweight. The figure for India was $63 \%$, for Tanzania, $25 \%$, for China $21 \%$, and for Brazil, $7 \%$. I selected these countries as representing some of the larger national populations and the fastest rates of growth. Globally, about a billion people are undernourished. Indeed, if population does increase to 10 billion, at least $80 \%$ of that growth will be in South East Asia, Africa and Latin America.

It is too early to accurately project population to the end of the next century, that is the year 2100 . However, agricultural technologists will tell you the lead time required for the effective spread of a major technological innovation in food production is on the order of 40-50 years. An example would be the widespread adoption of genetically modified crops. Thus, it is not irrational to contemplate a scenario for a population somewhere between 15 and 20 billion in 2100 . If we should succeed in doubling food production in the next 50 years, to feed a population of around 10 billion, we cannot wait to the year 2050 to say, "oh-oh, we'd better start doubling it again," in other words, four times the current levels. It is clearly much more difficult to increase agricultural production than to decrease it.

Food production is one of the most complex of our economic sectors, and, given the issues of sustainability, many of its parameters for success lie beyond the reach of technology, at least technology as currently conceived. Some of the very realistic threats to sustainability may even require a technological retreat, for example global warming.

Of course, the intervening variable in these projections for population growth could be a significant increase in the death rate due to (1) starvation, (2) an environmentally-caused decline in the birth rate, (3) disease and/or (4) war. Interestingly, any of the forces that would increase the death rate would likely generate a decrease in the availability of food, at least locally.

For purposes of assessing our long-term ability to produce food, I conclude that we should consider a world population in the area of 10 billion in the middle of the next century. Without a downward change in rates, we could then have an annual growth of around 150 million.

To feed 10 billion people 50 years from now, we will need to increase food production by at least an average of $1.5 \%$ per year to maintain even current levels of nutrition. To improve nutrition, we should consider an increase of $2.5-3.0 \%$ annual increase in calories, with a concurrent increase in the quality of those calories. While we will necessarily focus on wheat, rice, corn and millet, such a focus will not solve the nutritional quality problem. However, it seems likely that the per capita consumption of meats and poultry will decline, even in the more affluent societies. This, then, is the population-food challenge.

\section{TRENDS IN FOOD PRODUCTION}

Before we consider scenarios for how food might be produced in the 21 st century, we need to make an assessment of current trends in food production. This will not be an exhaustive tour of agricultural 
inputs. We'll focus on some of the most significant ones. These include trends in grain production, energy supplies, arable land, water, and climate. In other words, grain production depends fundamentally on these four independent variables. There are, of course, other variables, including the significant one of public and private investment.

Perhaps the most basic indicator of our status is the trend line in world grain production. In 1950, world grain production was around 631 million metric tons. In 1994 it was 1,747 million metric tons. This is 2.8 times the 1950 base. That figure is indicative of the Green Revolution. However, since 1990 world production has leveled off at an average of about 1,700 million metric tons, with some yearto-year fluctuations due to variations in rainfall in those grain-producing regions significant enough to generate exports.

We must also examine the per capita production of grain. In 1950 it was $247 \mathrm{~kg}$ per living human. In 1994 it was $311 \mathrm{~kg}$. That is 1.3 times the 1950 base. Another apparent gain. However, we need a more timely look. From 1985 to 1989 the average annual production was $327 \mathrm{~kg}$ per capita. From 1990 to 1995 it was $316 \mathrm{~kg}$. There is significant slippage from the average in the 1980s.

There is much concern among agriculturists about why this slippage is happening. Some agricultural economists are arguing that the Green Revolution is faltering. Others, that agriculture is slipping in terms of cost-effectiveness. That seems clear for dairy producers in my bountious state of Wisconsin, where family farms are struggling. Some climatologists are arguing that global warming is beginning to show an effect. A warmer annual temperature of $2-3^{\circ} \mathrm{C}$, they argue, will have a negative impact in many of the world's major food-producing regions.

The trend line in carryover stocks is of more immediate concern to the world's consumers than year-to-year grain production. Carryover is defined in terms of the number of days of grain in reserve, based on current use. In 1963, world grain carryover stocks were at 190 million metric tons, which at that time was equivalent to 82 days use. In 1987 , carryover stocks were at 465 million tons, which was the equivalent of around 104 days use. 1987 was the peak year of reserves since world War II. In 1995, the reserve is at 298 million tons, equivalent to 62 days of use.

One concern is the impact of these declining reserve stocks given even a one-season crop failure or a series of drought years over a region, which could occur, for example in the band from Syria, through Egypt and across North Africa to Morocco - or in China or in India.

The second concern is how such a decreasing reserve will affect the price of grains. The grain futures market in the US is currently reflecting the low level of carryover stocks. At the same time China has growing purchasing power. It is obvious that a given year's production will have an effect on the reserves, but the trend line is disturbing as one considers long-term strategies. It is also obvious that a declining reserve could stimulate more production, assuming some other major forces do not intervene.

It should be noted that the trend in production of soybeans and meat has increased fairly steadily and significantly since 1950, an improvement in nutrition, but that has occurred largely in the industrial countries and is probably a function of feed grain opportunities as much as food grains.

The Green Revolution has clearly led to increases in food since World War II, and it is, to me, an obvious reason for increases in world population. That revolution has been a montage of improved grain varieties, pest control, fertilizer, mechanization and socio-economic infrastructure. But now let's focus on my stipulated independent variables.

\section{Energy}

One thing has often been missed in analyses of the Green Revolution. Its successes are indelibly linked to the supply and price of fossil fuels. Let's give that statement some direction. Our food supply is currently dependent on abundant and relatively inexpensive supplies of oil, natural gas, and coal. Studies of the amount of fossil fuels flowing into food production, and food calories flowing out, 
show that industrial agriculture is fairly close to a zero-sum game. In feed corn in the US, we are putting more fossil fuel calories in than we are getting out. In another facet, corn is being processed to produce ethanol, which is then used to fuel the tractors that are used to harvest corn. Such systems are tenable if fossil fuels are abundant and cheap. That is obvious. But fossil fuels are a depletable natural resource, and they are being depleted. The rate of depletion will increase as a function of economic growth in Asia. The question is how and when to phase in alternatives, with attention to the lead time required to do that.

There is one interesting trend in this zero-sum energy game that may be reflective of the future. That is, world fertilizer use. Central is ammonium nitrate with petroleum as its raw ingredient. Energy is also used in the mining and processing of phosphorus and potash, which are also depletable resources. In 1950 world agriculture used about 14 million tons of fertilizer with a per capita use of $5.5 \mathrm{~kg}$. In 1994 that figure was 121 million tons with a per capita use of $21.6 \mathrm{~kg}$. This is also reflective of the Green Revolution. However, those figures peaked in 1989 and have since shown a steady decline. Within national boundaries, Russia shows a significant decline in the use of fertilizer; however, China shows a significant increase. Fertilizer use in the US has declined, but not precipitously.

Why is there a decline in the use of fertilizer, particularly ammonium nitrate? Price is certainly a factor. But some farmers in my state of Wisconsin are reporting that they are seeing a negative relationship between increased use of fertilizer and yields. There is also a growing resistance in the sustainable agriculture movement to chemical fertilizers, but that is still a small factor overall. Some American farmers are not using any chemical fertilizer now. Yields per hectare usually show a decrease, but profits per hectare generally show an increase.

Looking to the future, it would appear that a doubling of food production in the next 50 years must absolutely look for alternatives to fossil fuels. Most forecasts for petroleum (oil and natural gas) project a peak in world production sometime in the early decades of the century and a decline after that. Coal will become more important, but costs to clean up the atmosphere will increase. The forecasts on petroleum and coal assume political stability and economic structures to exploit fossil fuel reserves in such regions as the Arabian Gulf, Azerbaijan, China and North America. That is of particular concern to countries like Israel, where coal is imported to generate electricity.

As with forecasts of population numbers, we must guard against quibbling over the dates of such fundamental shifts in energy sources and start to phase in alternative sources of energy. There may be some very beneficial surprises ahead in that regard, at the biological level. I'll explain that a bit later. In the meantime, we are all well aware of the economic forces against presumptive shifts in the patterns of energy production and consumption. In my many discussions with Arab oil producers over the years, the central policy issue has been how to program the rate of depletion for petroleum, with the assumption that (1) the resource would be depleted and (2) with the goal of optimizing profits. It's a tough game, full of risks to the producers. Production investments are immense, and those investments will be defended against alternative sources of energy.

\section{Arable Land}

Approximately $99 \%$ of the world supply of arable "surface" is derived from terrestrial ecosystems with the percentage from aquatic systems shrinking. There are many disagreements about what arable land is and what is potentially available. However, under current land use patterns the availability of arable land at the world level is around 0.27 ha per capita and shrinking. That figure for the US is 0.7 ha per capita, which many of us still believe is the platform of American economic security over time. So be it, if we are not Keynesian economists and therein opposed to the use of the index of Gross Domestic Product (GDP) as the route to utopia.

Worldwide, the availability of cropland per capita is decreasing in a fairly tight correlation with population growth, but arable land is also being lost due 
to excessive pressure on the environment and to urbanization. An unavoidable figure is that, during the past 40 years, nearly one-third of previously cropped land has been abandoned because of changing land use, soil erosion and salination. Most of the replacement has come from land made available by removing forests. Agriculture accounts for $80 \%$ of the annual world deforestation.

It is possible that such trends in availability of arable land could be reversed. One obvious way, to be discussed shortly is increased irrigation. However, it seems that for increasing food supplies, it is more likely that we will seek to increase yields per hectare than increasing the amount of land. The Jordan river valley would be an example. In a modest example of recent research in the US, soil scientists are using computer imagery and computer controls to assess land quality on a micro-scale and then apply differing amounts of fertilizer, water, and pesticides, as they cultivate a given field. The goal is to at least hold yields steady, but reduce the negative impacts of over-use of Green Revolution inputs.

Whether cultivation of additional lands, reclamation of damaged lands, or intensification of production, such production will be more capital intensive, and, I will argue, likely more human-labor intensive. This raises the question of whether more of that intensification will be in the industrial countries, resulting in greatly expanded trade, or in the developing countries, or both.

Given the likely increase in fossil fuel costs for highly-industrialized agriculture, it would seem that intensification of production must come in the developing countries in a very significant way. That will necessarily be labor intensive. Industrial countries will have other menus of issues that will distract them from huge increases in food exports, particularly if welfare grants to very poor countries are the basis of distribution.

\section{Irrigation}

Irrigation is here used as a proxy for water available to crops. Precipitation, thus rainfed agriculture, will be considered in the next sub-section on climate.
About one-third of the global harvest comes from the $16 \%$ of world cropland that is artificially watered. The first conclusion is that our food supplies are more reliant on rain-fed agriculture than on irrigated land. That is true, but potentially misleading, for three reasons:

1. Irrigated land appears about three times as productive per unit as rain-fed land. This is probably more a function of investments in irrigation systems rather than the inherent arability of the land, although natural fertility is a factor. Nowhere is this more obvious than in Israel. Having grown up on an irrigated ranch in the western US, I am keenly aware of what it takes to make the desert bloom. On my family's land, we have lush fields with supplemental water. Without it, we have sagebrush.

2. As the demand for more cropland increases, we will turn increasingly to arid lands previously considered as too marginal for agriculture - if there is water.

3. Supplemental irrigation will be seen as a way to increase production on lands previously managed as rain-fed. Syria is a major example in that regard, in the wheat areas around the upper Euphrates, but also in the olive groves on the volcanic plains south of Damascus and on the eastern slopes of the Golan. Another interesting case is Jordan, in the river valley, but also on the high plains west of Amman. However, as you may know, Jordan now has tight restrictions on the drilling of wells for irrigation water because of the demand for potable water in Amman.

If we back away from the examples, and look at global trends for irrigation, we see a similarity to fertilizer use.

In 1991, some 4 million hectares were added to the irrigation base, enough to lift per capita irrigated area slightly, to $45.2 \mathrm{ha}$ per thousand people. However, a long-term trend of slower irrigation expansion persists. Between 1961 and 1978, world irrigated area grew an average of $2.8 \%$ per year, but between 1978 and 1991, it grew by an average of $1.4 \%$ per year, half as fast. Perhaps more significant, 
per capita irrigated area peaked in 1978 and has been falling since then. In 1991, per capita irrigated land was 5.4\% lower than in 1978.

The cost of adding new irrigation capacity has risen substantially in many regions, making new investments harder to justify economically. Concerns over environmental and social harm have slowed the pace of investments in some large dam projects, for example in India. Salination is an issue in almost every irrigated area in the world. One of the more interesting developments is the proposed massive dam on the Yangtse River in China. One could take bets on whether or not it will actually be constructed. I think it is problematic, because of the immense scale of the dam and the possibility of structural failure. In the US the Commissioner of the Bureau of Reclamation has stated, "federallyfunded irrigation water supply projects will not be initiated in the future." He's probably wrong. The Missouri River diversion proposal is still on the table.

There are interesting competitions for water in developing urban centers in arid regions. One such interesting case is Jerusalem, which currently has an urban population of around 570,000. According to a recent article in The New York Times (Sept 18, 1995), demographers at the Jerusalem Institute for Israel Studies foresee a population of 750,000 in Jerusalem by 2010 . That won't happen without a substantial increase in water allocated to the city. Jerusalem may be fortunate, given the recent delineation of a major aquifer on the East Side of the Judean Hills. That discovery adds an estimated 80 million cubic meters of ground water to the regional budget. This is not a significant addition to the annual water budget of Israel at an estimated 1,800 million cubic meters, but it is equivalent to about $40 \%$ of annual Palestinian consumption on the West Bank. Nevertheless, that aquifer will be important to both Israelis and Palestinians, considering the pressure to drill additional wells in the Judean and Samarian hills. I use the Jerusalem case as an example of the complexity of allocation of water, including the pressures against irrigation's allotment.
For long-term planning, there are two significant underlying points in this example. (1) First, aquifers are depletable. Most geologists now agree there's no such thing as "fossil" ground water, that is, water laid down during the last glaciation. Aquifers are not closed systems as is petroleum. But there is repeated evidence of societies drawing out ground water faster than it is recharged. (2) Urban areas are increasingly in competition with agriculture for water, from whatever source.

The future of agriculture in such areas as Israel and the Imperial Valley in California is tied to the availability of irrigation water in competition with urban areas. If the goal is to double yields in the next 40 years, that conflict will become acute.

\section{Climate}

Most of us spend a good deal of our waking hours thinking about, and exclaiming over, seasonal weather. Why was the summer so hot and humid in my home town of Madison, Wisconsin this year? Will the winter rains hold up in Israel again this year? People here must keenly remember the drought that persisted for five years not so long ago. In that period, Israel reduced its allocation to irrigation.

We may soon have some capability for predictions on medium-range climate changes. On a much longer time scale, climatologists are now advancing some of the most fascinating conclusions of any in the natural sciences in the last decade or so. While there are still arguments, there is a growing belief that glacial cycles are more periodic than episodic. That belief posits a theory that glaciation, or at least glacial climates, have occurred in 100 thousand year intervals all the way through the Pleistocene, over the last 2 million years, maybe 2.5 million years. The theory is that we are slowly, but inevitably, approaching the next period of glaciation. Movement into a glacial climate proceeds slowly and erratically, movement out tends to move more rapidly.

The latitude of Tel Aviv may be among the more sensitive regions to such monumental changes, 
because it is on the boundary between the subtropical convergence of the low latitudes and the circumpolar vortex of the high latitudes. A cooling trend would bring the westerlies and the winter rains further south, even into the reaches of the Sahara. A warming trend would bring the deserts further north. Interesting stuff, and it may mean a change for the residents here a thousand years from now, or two thousand.

In the meantime, and for the next century, we have another short-term concern that is not unrelated to these millenial changes. That is the issue of global warming.

The Intergovernmental Panel on Climate Change is a group of 2500 scientists that advises parties to the 1992 treaty designed to negotiate reductions in heat-trapping greenhouse gases like carbon dioxide. Their conclusion, released in September of this year, is that "the earth has entered a period of climatic change that is likely to cause widespread economic, social and environment dislocation over the next century if emissions of heat-trapping gases are not reduced."

They further conclude that "global climate change is indeed in progress and that at least some of the warming is due to human action, specifically the burning of coal, oil and wood." According to draft sections of the new forecast, some of the predicted effects of climate change may now be emerging with increasing clarity.

We'll pick out a couple that could have an impact on food production:

(1) A continuing rise in average global sea level is likely to amount to a foot and a half by the year 2100. This would inundate a series of river deltas, including such deltas as the Mississippi, the Nile, the Mekong and Yangtze, which are major agricultural areas.

(2) An increase in extremes of temperature, dryness and precipitation will likely emerge in some regions. If this is true (remember the IF), we would expect a weakening in the westerlies (thus winter rain) at the latitude of Tel Aviv, averaged over decades. We would also expect increasing heat and humidity over the Corn Belt in the US and drought in the Northeastern US.

(3) Wheat belts of North America and Russia could expand.

(4) In general, deserts in the heartlands of continents would become drier.

Such conclusions are not "out of the blue." There is evidence of such warming expressions during the height of the most recent inter-glacial, about 6000 years ago. There is also overwhelming evidence of a cooler and wetter climate across North Africa 15,000 years ago, indeed an epoch that probably lasted 60,000 years.

It is worth noting that human beings emerged during the Pleistocene, in the last two million years. But agriculture emerged only in the last 10,000 to 12,000 years, perhaps some 2000 years after the height of the last glaciation. It would be fascinating if we knew the climate of this region as people began what many believe was the world's first irrigation at Jericho. Did they do it, because of declining westerlies? Did Abraham's tribes migrate to the springs of the Dan some 4000 years ago because of drought in the upper Tigris-Euphrates?

\section{Summary of Technical Inputs}

Let us now sum up this short analysis of agricultural inputs. One might conclude, from the assessment of trends, that we would be lucky to maintain food production at current levels. However, that obviously won't be adequate to serve the needs of the world's people as the population pushes upward.

Many of the optimistic agricultural futurists project an intensification of classical Green Revolution strategies. It is my judgment that such strategies will not be adequate and in some cases will have a negative impact. There are two reasons:

(1) The declining rate of response is due to more than weather problems, because inputs are declining. The open question is whether the declining inputs are due to short-term market fluctuations or whether something more 
fundamental is going on. I have not discussed the problems with pesticides, which seem among the most troublesome. There are thus some growing technological flaws.

(2) There is one other, highly significant, trend, that is different from the technical inputs. This is the institutional trends at the global level that have become increasingly prominent over the past 40 years. The following summary is adapted from a lecture that Professor Dorner, an agricultural economist at the University of Wisconsin-Madison, gave in a summer forum at Madison this summer.

(i) First are the growing linkages, even interdependencies, between nations the world over. Not the least of these is the interdependence with fossil fuels. While we live in this world of increasing interdependence, practically all of our governmental institutions remain national and geared to addressing issues internal to the nation state. In some cases these institutions are intensely nationalistic. In fact, we have witnessed a successive breakdown and growing irrelevance of international governmental institutions at the very time that our respective economies have become increasingly integrated.

(ii) All economies, even those of the largest nations that were essentially self-sufficient a generation or two ago, are today highly dependent on international trade. A corollary of this increased trade is that national economies are less amenable to direction by domestic economic policies. Citizens demand action to improve their economic situation, but the necessary actions are only partially under the control of national officials.

(iii) The closest we have come to really transnational institutions with power to enforce its decisions are the increasingly complex multinational corporations. Although they have been much criticized for some of their international practices, often appropriately, it is almost impossible to conceive of the world economy functioning without them. In many commodities, world trade is dominated by the multi-nationals, and a large part of registered international trade represents the internal transactions of these international companies. It is apparent that decisions within the US agricultural sector, including at the level of production, are made by trade opportunities, with growing emphasis on feed grains, but also by issues of balanced trade, in other words feed grain and timber in exchange for manufactured goods. Such forces are several steps removed from the question of starvation, or even of optimal nutrition and from the question of sustainability of the land base.

(iv) Finally, the impact of our modern technologies on the environment has become less and less localized and increasingly international, for example, widespread deforestation, leading to the generation of carbon dioxide, and acid rain, which obviously don't recognize national boundaries.

One consequence is that geo-economic decisions are made on criteria other than sustainable food production, for example, agricultural lands tend to be treated as depletable resources. In addition, geopolitical decisions are often the crucial variable in how much is produced and where it flows. Such forces may also partially explain the apparent "weariness" of the industrial nations in granting aid to the less developed countries. We need to pay attention to whether these emerging international institutions abet or restrain global food production, including in those countries that are not major decision makers in the global private-sector network. Thus, the North-South dialogue enters a new phase.

\section{THE POTENTIAL FOR AN INCREASE IN GLOBAL FOOD PRODUCTION}

Now, let me turn to what are some of the strategies that will emerge from the laboratories and the policy think-tanks as we struggle to increase food 
production. And struggle we will. It is clear that such new strategies will be rigorously scrutinized by international economic decision-makers for their cost-effectiveness, as a condition of their adoption by both industrial farms and small farmers.

As I said earlier, I do expect a continuation of the strategies of the last 50 years. Some of these will fall by the wayside because of our understanding of growing risks. There are some other interesting emerging concepts, and that is where I will focus my attention. This is a sample, not a survey. In addition, my selection of these concepts does not mean that I feel they will lead to a solution of the food supply situation. Further, my selection does not imply an ethical judgment of their use. I do believe they will be considered.

\section{Technology and Bio-technology}

This is the most discussed. In the September 1995 issue of Scientific American, Donald Plucknett and Donald Winkelmann summarize the potential in this area in an article titled Technology for Sustainable Agriculture.

As an example, and on the issue of pest control, they cite the concept of Integrated Pest Management, involving the synthesis of insect attractants that occur naturally in the insects as pheromones. These chemicals can be used to interfere with the normal reproductive cycle of common pests. Efforts are under way to modify plants to incorporate insect pheromones in the genomes of the plants.

Other geneticists are working on making plants more efficient in converting sunlight, nutrients and water into food and fiber products. Conventional plant breeding now boosts yields by roughly $1 \%$ annually. Plant breeders are working on the genetic basis of many traits, including disease and insect susceptibility, biochemical composition and nutritive value. Some optimist bio-technologists predict the ability to make new kinds of "synthetic" plants by crossbreeding, for example, converting annual grains into perennials. Others expect to engineer synthetic traits, conceived in the laboratories, directly into crop lines.
The conclusion of Plucknett and Winkelman is interesting. "Farmers will have to confront formidable challenges in learning to manage ever more advanced technologies in ways that will increase the productivity of their resources while protecting the environment. That complex goal should be within reach of richer countries, where (ironically) food is already abundant and affordable, population growth is slow and mechanisms exist for resolving at least some environmental problems associated with agriculture. But it will surely be a daunting task in the developing world, where about a billion people are being added each decade, where roughly that number are already malnourished, and where social capital for environmental protection is severely limited." In spite of that stern summary, let us proceed in our analysis. One of the most interesting research efforts revolves around the concept of net primary productivity. Net primary productivity is a function of solar energy at the earth's surface, and it means the amount of "surplus" carbohydrates available after plants meet their respiratory needs. The natural strategy of plants is to store next seasons's needs either in seeds or in roots. The store becomes available to animals, who have mobility to search for food, but do not have chlorophyll in their skins for primary production. Plant breeders, so far, have relied on the strategy of inducing the plant to shift its net primary production from stems, leaves and roots into fruit, including seeds. Now, there is the glimmer of an idea that we could create plants to actually increase their net primary productivity. One important variable will be the available solar energy at the surface of the leaf. Such a breakthrough would lend emphasis to technology that would shift our reliance to solar and away from fossil energy. We might call this a "blue sky idea," but the double meaning is apt.

A paper by Vitousek, Ehrlich, Ehrlich and Matson, in a recent issue of BioScience points up the vital importance of the issue of net primary productivity. In that paper, the authors point out that about 1.15 pentagrams of plant material (largely food grains) is harvested annually, resulting 
in 0.76 pentagrams for direct human consumption. About 0.39 pentagrams (34\%) is wasted or lost to pests or spoilage. Agricultural animals consume about 2.84 pentagrams, with a conversion efficiency to human food of about $10 \%$. Total human use is about 7.2 pentagrams, including wood products, or about $3 \%$ of the biosphere's total annual NPP. So, it would seem that humans exert a relatively minor force in the plants ability to store solar energy. However, and this is the problem, the authors assert that humans are co-opting up to $40 \%$ of potential terrestrial productivity in their farming and grazing practices in woodlands, grasslands, and savannas, and through the degradation of croplands. Their conclusion is that, without fundamental changes in agricultural practices, we will be at the biological precipice with a world population of 10 billion. This is probably the most gloomy forecast I have seen. However, the analysis suggests the possibility of a major research effort focusing on the issue of net primary production. That effort would involve an array of means to improve the photosynthetic efficiency of plants and radically cut wastes and degradation. It would be interesting to analyze how such a scenario would play out given a global warming of about $2^{\circ} \mathrm{C}$ because of an increase of atmospheric carbon dioxide.

Another interesting concept has to do with the cycles of elements essential to organic processes, such as oxygen, hydrogen, carbon, and nitrogen. We probably are approaching the end of the 400-year influence of naturally-produced hydrocarbons, which are reduced carbohydrates. In the future, the focus will shift to solar radiation at the surface of the earth and to carbohydrates as a source of energy, including the role of carbon dioxide. We would then examine the balance of carbon dioxide in the atmosphere, considered as a resource as well as a pollutant. While we might not reach the point where we could negotiate global carbon dioxide balances, we very likely will try to manipulate the plants capacity to use it. The same is true of oxidation processes, first at the physical level, such as the hydrolyzation of water to generate hydrogen, or the oxidation of hydrogen to create water, and then in respiratory processes. In a similar vein is the nitrogen cycle. Nitrogen is the most abundant element in the atmosphere. It is just not available to plants in its atomic form.

Element cycles are obvious reactions known to every freshmen in chemistry, but we have not generally applied those concepts rigorously to the technology of food production, with one major exception - our attempts to genetically manipulate grasses such as corn so that they have the nitrogen fixing capability of legumes. Indeed, application of cycles of the basic elements seems conceptually to be more risk free and more environmentally sustainable than many current practices, particularly those involving hydrocarbons.

Beyond the genetics and chemistry laboratories, there are, I believe social and economic forces that will come to the forefront as critical elements in the world food budget. My thoughts in this area are more tentative than in the area of technology, but I'll lay them out.

\section{Competition and Cooperation}

We will be increasingly concerned with the degree of competition and cooperation allowed and/or designed. Competition and cooperation are natural biological phenomena. Humans are biologically competing predators, and, at least so far, survivors in an environment that is highly competitive. In human affairs, market competition is argued as the most efficient way to produce and distribute resources. A basic assumption is one of open-ended supplies of resources and confidence in technology's ability to substitute materials and processes. The trend to international business structures may appear, on the surface, to be an expression of the advantages in competition, but I think that could be wrong. The complexity of the structure requires a greatly increased level of cooperation to avoid dissonance or chaos. Examples are the General Agreement on Tariffs and Trade, standards set by international banking institutions, attempts to modify the fluctuations in currency, and geo-political forces at work on trade balances. The political 
upheaval currently on-going in the US is, at least in part, a conflict between large international enterpreneurs striving for more political order, and small businesses, feeling pushed around and striking out for fewer regulations.

Much of agriculture falls in this category of small business. Just imagine trying to put together an effective global network of food production and distribution based on need as well as demand for a population of 10 billion.

It does seem that humans strive for cooperation as a balance to competition. What we are doing is adding conscious behavior to the widespread and advantageous symbiotic behavior expressed in the natural world. This is explicated through agencies designed to distribute wealth for the general welfare, agencies to protect environmental quality, and agencies of domestic and international peace.

My judgment is that, with a human population of 10 billion in 50 years and perhaps 20 billion in 100 years, the pressure will increase greatly for an increasing commitment to cooperation. Central will be the equitable and low-cost distribution of food. A major consequence of regional shortages without cooperation will be increasing rates of migration toward those areas with a combination of the best arable land base and the most sophisticated technology. Within nations, a consequence of shortages would be the radical breakdown of social structures in a downward spiral to a population level the local environment would support, in other words, Malthus at the local level.

\section{Management of Resources}

Part of a commitment to cooperation will require extremely careful management of resources. The classic depletion curve for stock resources will increasingly come under criticism. In the agricultural example we have seen such cooperation in attempts at fossil fuel conservation and a decreased use of chemical pesticides. Such things as carbon, nitrogen and oxygen cycles and solar energy are, by definition renewable. At that level, I would argue that we will need a more sophisticated level of cooperation than we have achieved in the exploitation of depletable resources, because of the infrastructure required to pull off such complex manipulations. For example, it would seem difficult to employ the technique of a cartel in the atmospheric management of carbon dioxide.

\section{Institutions for the Dissemination of Bio-Technological Innovations}

Arguments will increase over the ownership of biotechnological innovations at the level of individual genetic modifications and at the level of biotechnological processes. Investments are large and profit potentials are huge. The resulting infrastructure is startlingly different than earlier economic patterns of subsistence agriculture, the family farm, or even the Israeli kibbutz, where decision-making has been maintained at the ground level. And, it will be increasingly difficult to extract profits from such proprietary values in the most densely populated regions of the world. The focal test of this situation will likely be China. There are two underlying issues: (1) First is whether and how such innovations will spread beyond the more affluent and more industrial societies. (2) Second is the question of whether we can or will turn over food production to giant, international corporations or to central governments.

\section{Sustainability}

My basic position in this paper has been that we will not transform food production to systems of chemical vats and industrial production lines, where the inputs would be the basic nutrients plus chemicals and/or genetically-modified bacteria. For one thing, food is so much a part of our cultures, even our ethnic diversity. Food is indeed the spice of life as well as the basis of survival. That is perhaps most evident right here, at the juncture between the spices of the Orient and the cuisines of the Mediterranean. We will continue to rely on natural forces with inevitable stochastic variations. The 
issue thus is whether and how we continue to live within the outer and limiting boundaries of those natural variations, or whether we try to narrow the risk inherent in the variations, as we move closer to critical boundaries.

In that regard, a breakthrough in water supply might come with cheap desalination from the oceans, with emphasis on the word cheap. I tend to agree with the Ehrlichs that we could approach the limits set by net primary production within the next 100 years. Climate variability seems the least amenable to technological manipulation, so that climate may well be our outer limit, particularly if we muck up long-term trends in the process.

\section{Population}

Finally, we must return to the issue of human population. I believe that population as related to food supply is the central political issue of our time, though I'm prepared to debate the point. Some may argue that the availability of resources is openended. In that scenario, would a population of 100 billion be tenable? For others, the issue is whether and where we might level the population into a steady-state field of 10 billion or fewer. Naturalists will describe a natural population curve, characterized by exponential growth, followed by a crash, and then another slow recovery. That may be our fate.

There is much ethical debate against controlling the birth rate. The opponents to control argue for the natural process. However, there seems to be a strong consensus that we should prevent a high death rate - unless we accept a kind of natural triage, one which says, in effect, you're really on your own. Yet, a varying death rate is also a natural process.

I cannot imagine a willful return to the conditions of neolithic times or paleolithic times. Thus, a central question is whether we manage populations in the patterns we have chosen to manage resources. The alternative is a climb up the staircase as we try to produce more and more food. The steepness of that staircase is driven basically by the rate of increase of population. That, in itself, doesn't seem so diabolical. But, this staircase, I believe, has several characteristics that add to the difficulties.

First, population grows in exponential terms, as a percentage of the base, thus the steepness increases over time. While at least some argue that the curve will level off, we are most reluctant to accept an exponential decrease, which would mean death by starvation.

In modern times, there is yet no indication of an end to the climb. There is no top floor, indeed no landing on which to catch our breath.

Finally, we find ourselves riding on a kind of escalator that varies in its speed, or can even reverse direction. The variation or the reversal is due to fluctuations in production. We carefully set our goals, based on long-term projections of need. A technological discovery can help. So we can stand on one step and let new developments carry us upward. Then that technology begins to falter. Natural and economic vagaries can quite suddenly reverse the direction of the escalator, so that we must climb faster just to stay in place. If we are producing many consumer goods, such as computers, we celebrate our gains, or shrug off our losses. But this is food! You can't eat a computer.

\section{References}

Bingham, Wolf and Wohlgenant, Resolving water disputes: Conflict and cooperation in the United States, the Near East, and Asia, Irrigation support project for Asia and the Near East, Nov., 1994.

Brown, Who will feed China? World Watch, Sept./Oct., 1994.

Brown, Kane and Roodman, Vital Signs 1994, Worldwatch Institute.

Brown, Lenssen and Kane, Vital Signs 1995, p. 94, Worldwatch Institute.

Cobb, Halstead and Rowe, If the GDP is up, why is America down? The Atlantic Monthly, Oct., 1995.

Dorner, Peter, Food, population, energy and the environment in the global economy in the twenty-first century, Presented at UW-Madison Summer Forum, "Will There Be Enough Food on the Table?" June 20, 1995.

Goldberger, Passions set in stone: Whose Jerusalem is it? The New York Times Magazine, Sept. 10, 1985.

Harris, World agriculture; Regional sustainability and ecological limits, Center for Agriculture, Food and Environment, Tufts University, Jan., 1995.

Islam, Population and food in the early twenty-first century: meeting future food demand of an increasing population, International Food Policy Research Institute, 1995. 
No Author, A 2020 vision for food, agriculture, and the environment, International Food Policy Research Institute, June 13, 1995.

Pimentel and Giampietro, Food, land, population and the U.S. Economy, Carrying Capacity Network, Nov. 21, 1994.

Plucknett and Winkelmann, Technology for sustainable agriculture, Scientific American, Sept., 1995.

Postel, Last Oasis, Facing Water Scarcity, Worldwatch Environmental Alert Series, W.W. Norton, 1992.

Rosegrant, Abcaoili-Sombilla and Perez, Global Food Projections to 2020:Implications For Investment, 1995.
Seckler and Cox, Population projections by the United Nations and the world bank: Zero growth in forty years, Center for Economic Policy Studies, Winrock International Institute for Agricultural Development, Sept. 1994.

Stevens, William, K. Scientists say earth's Warming could set off wide disruption, The New York Times, p. 1, Sept. 18, 1995.

Vitousek, Ehrlich, Ehrlich and Matson, Human appropriation of the products of photosynthesis, BioScience, 36(6), June, 1986.

Waggoner, How much land can ten billion people spare for nature?, Council for Agricultural Science and Technology, Feb., 1994. 


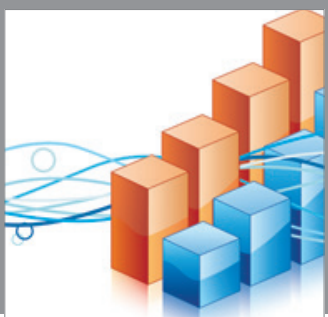

Advances in

Operations Research

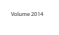

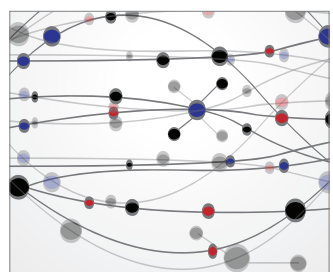

\section{The Scientific} World Journal
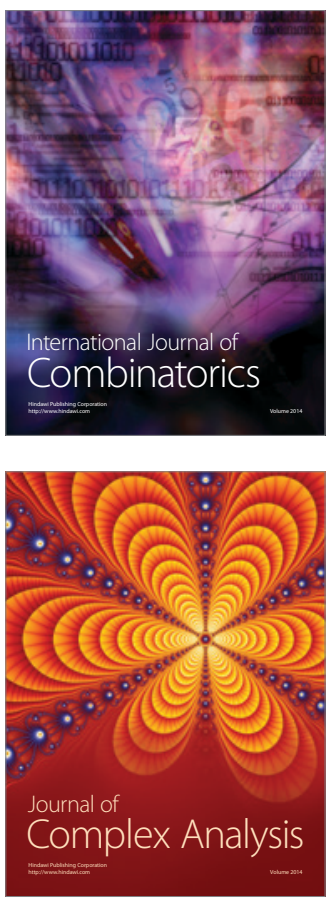

International Journal of

Mathematics and

Mathematical

Sciences
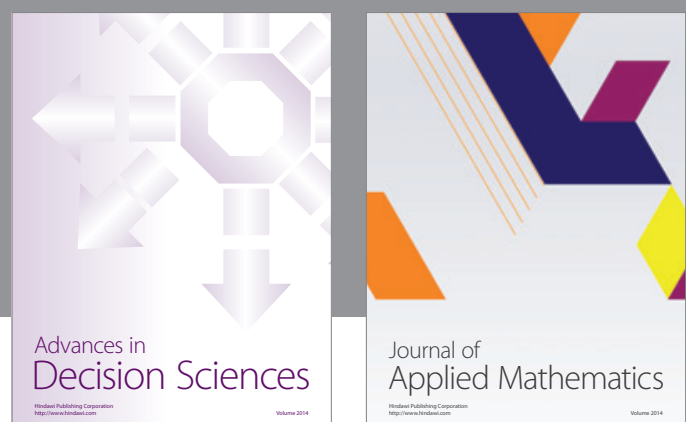

Journal of

Applied Mathematics
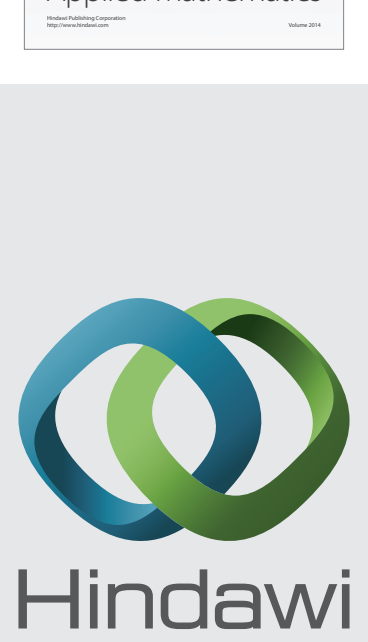

Submit your manuscripts at http://www.hindawi.com
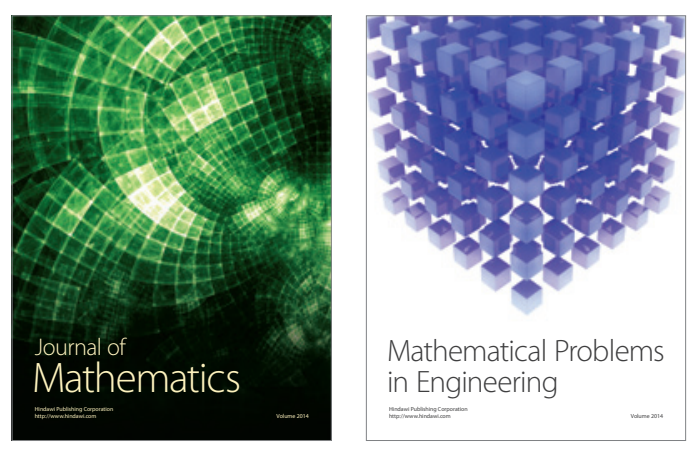

Mathematical Problems in Engineering
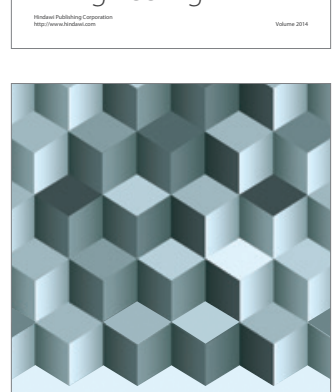

Journal of

Function Spaces
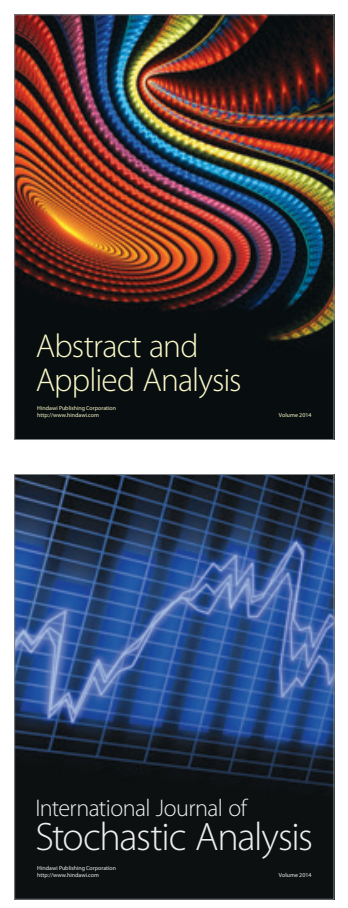

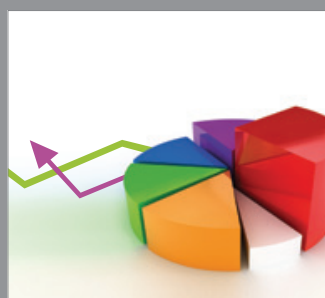

ournal of

Probability and Statistics

Promensencen
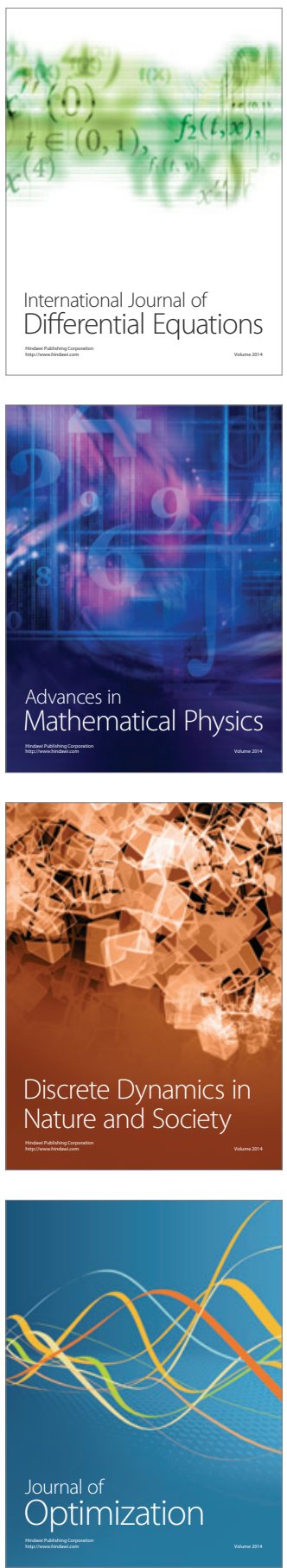